\title{
1 Image processing on meso-scale photographs of brittle shear zones
}

2

3

4

5

6

7

8

9

6

Poorvi Hebbar ${ }^{1}$, Soumyajit Mukherjee ${ }^{2 *}$, Narayan Bose $^{2}$

1. Department of Computer Science and Engineering, Indian Institute of Technology Bombay, Powai, Mumbai 400 076, Maharashtra, INDIA

2. Department of Earth Sciences, Indian Institute of Technology Bombay, Powai, Mumbai 400 076, Maharashtra, INDIA

*Author for correspondence: smoumyajitm@gmail.com, smukherjee@iitb.ac.in

1 Statement: This article is a non-peer reviewed preprint, submitted to EarthArXi. The article has been submitted to the Journal of Earth System Science for peer review. 


\section{Image processing on meso-scale photographs of brittle shear zones}

Poorvi Hebbar ${ }^{1}$, Soumyajit Mukherjee ${ }^{2 *}$, Narayan Bose $^{2}$

1. Department of Computer Science and Engineering, Indian Institute of Technology Bombay, Powai, Mumbai 400 076, Maharashtra, INDIA

2. Department of Earth Sciences, Indian Institute of Technology Bombay, Powai, Mumbai 400 076, Maharashtra, INDIA

*Author for correspondence: smoumyajitm@gmail.com, smukherjee@iitb.ac.in

\section{Abstract}

Study of structures and fabrics from different scales of observation is an indispensible first step in structural geology and other branches of geoscience. We process three selected images of brittle shear zones from quartzite, limestone and schist samples using various methods, steps and filters. Such exercises more effectively detect brittle planes when the planes are not too closespaced and devoid of white fault gouge. Edge detection methods using fuzzy logic seems to be

41 one of the best methods to detect brittle shear planes more distinctly in meso-scale from

42 photographs acquired from ordinary cameras. Notwithstanding, structural geologists'

43 identification and categorization of structures in the field with naked yet "trained" eyes or in

44 other scales of observation continues to be indispensible.

Words: 119

Keywords: Image interpretation; mathematical method; shear zone; structures 


\section{Highlights:}

I. Image processing techniques applied to brittle shear zones photographs, to enhance images

II. Discussion made on usefulness of such exercise in better identification of shear planes

\section{Introduction}

Correct geological interpretation of structures documented in field or from other scales of observations (Mukherjee 2021) has been of paramount importance in structural geology. Fieldsketches were done profusely by the field geologists (Genge 2020) before cameras became handy. Subsequently, with the advent of digital cameras and smart phones (Novakova and Pavlis 2017), photography and other structural geological activities in the field became quite easy. Having a huge space in the electronic device, geologists now take numerous photographs of geological structures. However, after getting back from field, one may note that not all photographs are of good quality, or in few images a very detail of structures are required to be presented. In such cases, geological snaps can be required to undertake image processing. However, if the primary image is poor, chances are that image analysis can help to recover features with a limit (Heilbronner and Barrett 2014). One of the main outcomes of image analysis in structural geology is to enhance the geological feature of key interest (Bjørnerud and Boyer 1996) in an unbiased, reproducible, quantitative and time-saving way (Bons and Jessell 1996).

\section{In applied structural geological contexts, images have been processed for seismic (Misra and} Mukherjee 2018), boreholes (e.g., Cornet 2013), microstructures (e.g., Mokhles et al. 2019), remote sensing (e.g., Sulaksana and Hamdani 2014) etc. Matlab programme has recently been 
82 developed to study fracture patters (Healy et al. 2017). Image analyses if done carefully can

83 produce a good number of following outcomes (Bjørnerud and Boyer 1996) calculation of object

84 areas, perimeters/lengths, color/grayscale magnitudes, and for lenticular objects- axial lengths,

85 orientations, $x-y$ centers, point-counting, strain analysis, areal estimation and assessment of

86 lattice and grain-shape preferred orientation.

87

88

89 This work first time applies several standard image processing methods on structural geological

90 images take from meso-scale. These methods are image segmentation, fuzzy logic image

91 processing, bilateral filtering and comparison amongst various fracture detection filter

92 techniques. We finally compare different methods/techniques and comment on the practice to get

93 the best possible interpretation of geological photographs. Specifically speaking, photographs of

94 brittle sheared rocks were analyzes. The aim was to identify the brittle shear planes correctly that

95 can lead to correct interpretation of shear sense. The aim is important in structural geology since,

96 incorrect interpretation of shear sense can lead to misleading tectonic models (review in Dutta

97 and Mukherjee 2019). Fig. 1 presents the brittle shear plane terminologies well established in

98 structural geology.

99

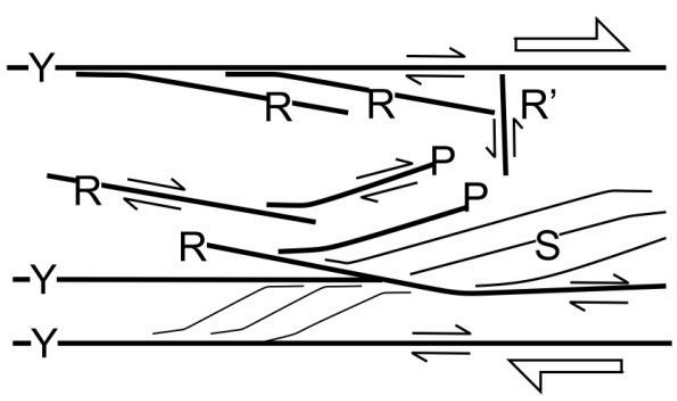

101 Fig. 1. Brittle shear plane nomenclature (reproduced from fig. 5.34 of Passchier and Trouw 102 1996). 


\section{2. Scope of work}

\section{2.1. Samples and Photography:}

106 Three images (Figs. 2a, 3a, 4a) of brittle shear zones with Y-and P-planes developed in different 107 degrees were processed by standard techniques. These photographs were captured using a Canon 108 PowerShot SX150 IS digital camera, and they come from the Inner Lesser Himalaya along the 109 Bhagirathi river section, Uttarakhand, western Himalaya, India. Low-grade meta-sedimentary 110 rocks, mostly quartzites (Fig. 2a) and low-grade metamorphosed limestones (Figs. 3a, 4a) and 111 thinly layered schists are present along this traverse. Detail of structural geology of the location 112 can be found in Bose et al. (2018), Bose and Mukherjee (2019), Biswas and Mukherjee (2022) 113 and Biswas et al. (2022). Sigmoid P-planes are bound by Y-planes were found from these images 114 in naked eyes, and in the field a top-to-N/NE back-shear is indicated. The timing of this specific 115 deformation from this Himalayan section has remained unknown till date. Shear zones observed 116 in (sub)vertical natural rock sections were photographed within around 11 a.m. to 02 p.m., i.e. 117 when maximum sun light is available. Rock sections perpendicular to the primary shear Y-planes 118 and parallel to the dip direction of such planes were photographed. 

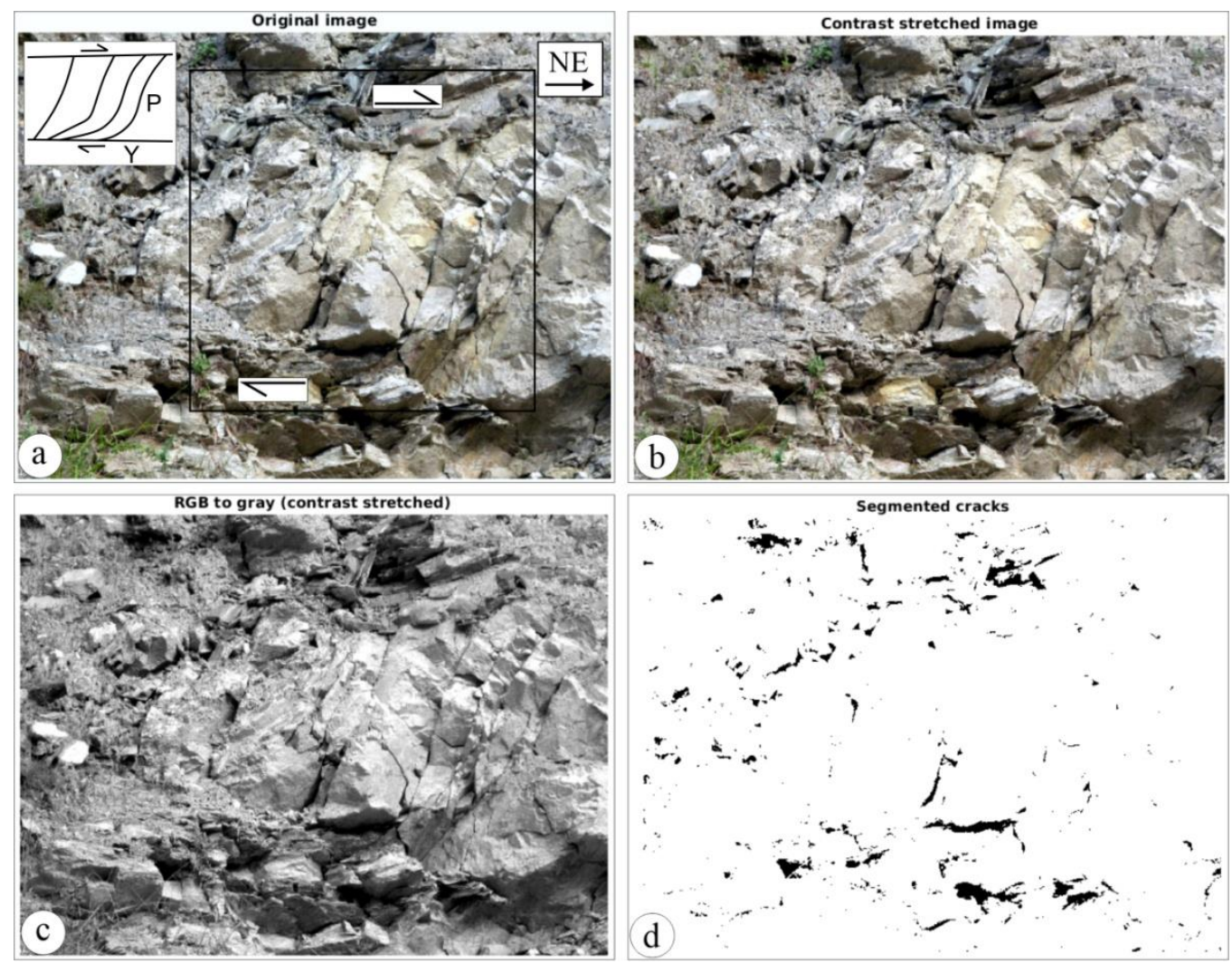

121 Fig. 2. See Table 1 for the codes. (a) Aaa; (b) Aab, (c) AAc (d) Aad, Width of image 3m. 122 Berinag Formation. Quartzite exposed at $30.8136^{\circ} \mathrm{N}, 78.6205^{\circ} \mathrm{E}$. 


\subsection{Image processing technique}

\section{3.}

While interpreting, figures have been named as " $X y z$ " in both main text as well as in Repository

127 1. Here $X$ stands for the methods applied, $y$ denotes figure number ( $a$ for Fig. 2a, $b$ for Fig. 3a

128 and $c$ for Fig. 4a), and $z$ represents steps used in the applied methods (Table 1). For example, $A b c$

129 will mean image segmentation applied on image $b$ with RGB to greyscale step involved. Matlab

130 programs were written for each of the image enhancement process (Repository 1). The image

131 analyses did not have any preferred choice for some specific fractures. For example, the grain

132 boundaries were also enhanced along with the brittle P- and Y-planes. Repository 2 presents

133 altogether 61 interpreted images, with about 20 each from the given 3 uninterpreted images. In

134 Section-3 "Discussions", we present few key images in order to compare the output.
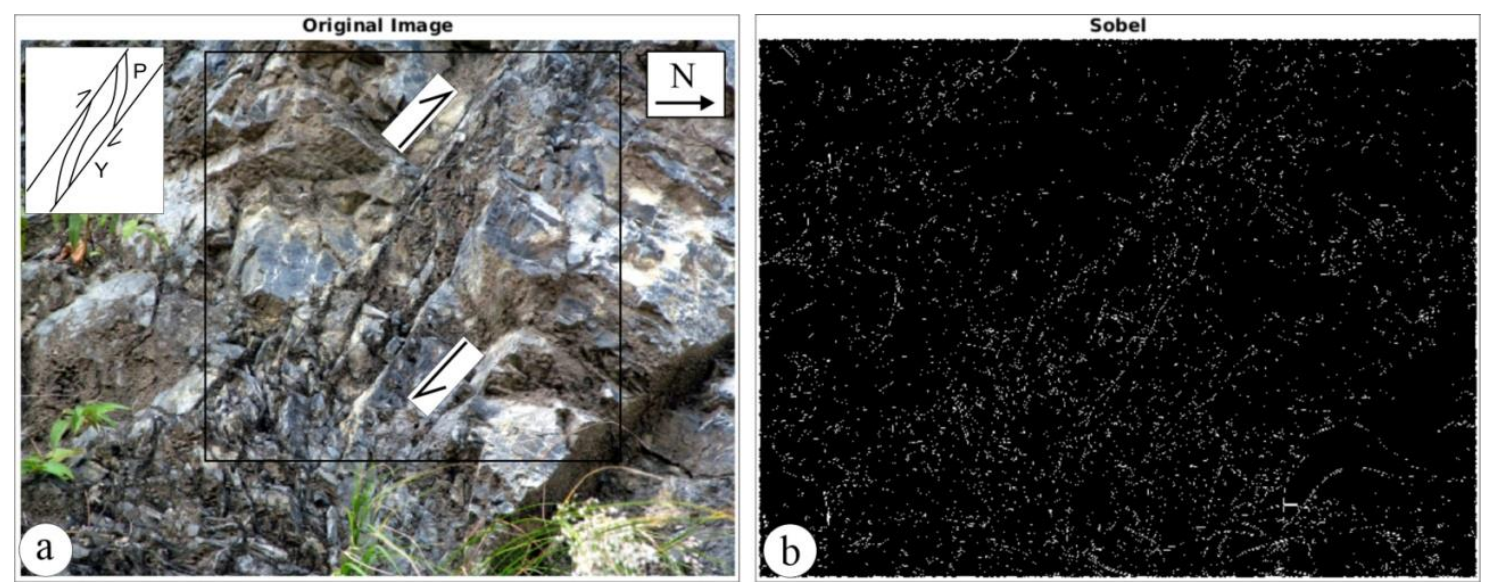

136 Fig. 3. See Table 1 for the codes. (a) Aba, (b) Dbc. Width of image 3m. Mandhali Formation.

$137 \quad$ Limestone exposed at $30.6802^{\circ} \mathrm{N}, 78.3497^{\circ} \mathrm{E}$. 
Table 1: Methods and Steps used in different methods.

\begin{tabular}{|c|c|c|c|}
\hline $\begin{array}{l}X \text { in } \\
\text { fig. } \\
\text { code } \\
X y z\end{array}$ & Method & $z$ in fig. code $X y z$ & Standard Approach (Internet ref) \\
\hline \multirow[t]{6}{*}{ A } & \multirow[t]{6}{*}{$\begin{array}{l}\text { Image } \\
\text { segmentation }\end{array}$} & $\begin{array}{ll}\text { a. } & \text { Original } \\
\text { uninterpreted image }\end{array}$ & \\
\hline & & b. Contrast stretched & $\begin{array}{l}\text { Contrast is augmented in the image: } \\
\text { Stretches the intensity range to span a } \\
\text { desired range of magnitudes. }\end{array}$ \\
\hline & & c. RGB to greyscale & $\begin{array}{l}\text { Alters RGB Images into gray scale. } \\
\text { Average value of the three colors per } \\
\text { pixel is taken. }\end{array}$ \\
\hline & & d. Segmented cracks & $\begin{array}{l}\text { Alters the grayscale image into a binary } \\
\text { image. Pixels in the input image are } \\
\text { altered with a luminance more than a } \\
\text { threshold level with the value } 1 \text { (white). } \\
\text { Other pixels with the magnitude } 0 \text { (black). }\end{array}$ \\
\hline & & e. Cleaned image & $\begin{array}{l}\text { Deletes isolated pixels (individual 1's } \\
\text { surrounded by 0's or vice-versa). }\end{array}$ \\
\hline & & f. $\quad$ Thinned image & $\begin{array}{l}\text { It removes pixels so that an object without } \\
\text { holes shrinks to a minimally connected } \\
\text { stroke, and an object with holes shrinks to } \\
\text { a connected ring halfway between each } \\
\text { hole and the outer boundary. }\end{array}$ \\
\hline \multirow[t]{5}{*}{ B } & \multirow{5}{*}{$\begin{array}{l}\text { Fuzzy logic } \\
\text { image } \\
\text { processing }\end{array}$} & $\begin{array}{ll}\text { a. } & \text { Original } \\
\text { uninterpreted image }\end{array}$ & \\
\hline & & b. RGB to greyscale & See $A-c$ above \\
\hline & & $\begin{array}{l}\text { c. } \mathrm{I}_{\mathrm{x}}: \text { Gradient of } \\
\text { intensities }\end{array}$ & $\begin{array}{l}\text { Gradient of the intensities of image pixels } \\
\text { along x-direction. }\end{array}$ \\
\hline & & $\begin{array}{l}\text { d. } I_{y}: \text { Gradient of } \\
\text { intensities }\end{array}$ & $\begin{array}{l}\text { Gradient of the intensities of image pixels } \\
\text { along y-direction. }\end{array}$ \\
\hline & & $\begin{array}{l}\text { e. Degree of } \\
\text { membership }\end{array}$ & $\begin{array}{l}\text { A membership function is assigned with } \\
\text { the specified type and parameters. } \\
\text { Designates a zero-mean Gaussian } \\
\text { membership function for each input. For } \\
\text { gradient value for a pixel to be } 0 \text {, it } \\
\text { belongs to the zero membership function } \\
\text { with a degree }=1 \text {. If sx and sy are the }\end{array}$ \\
\hline
\end{tabular}



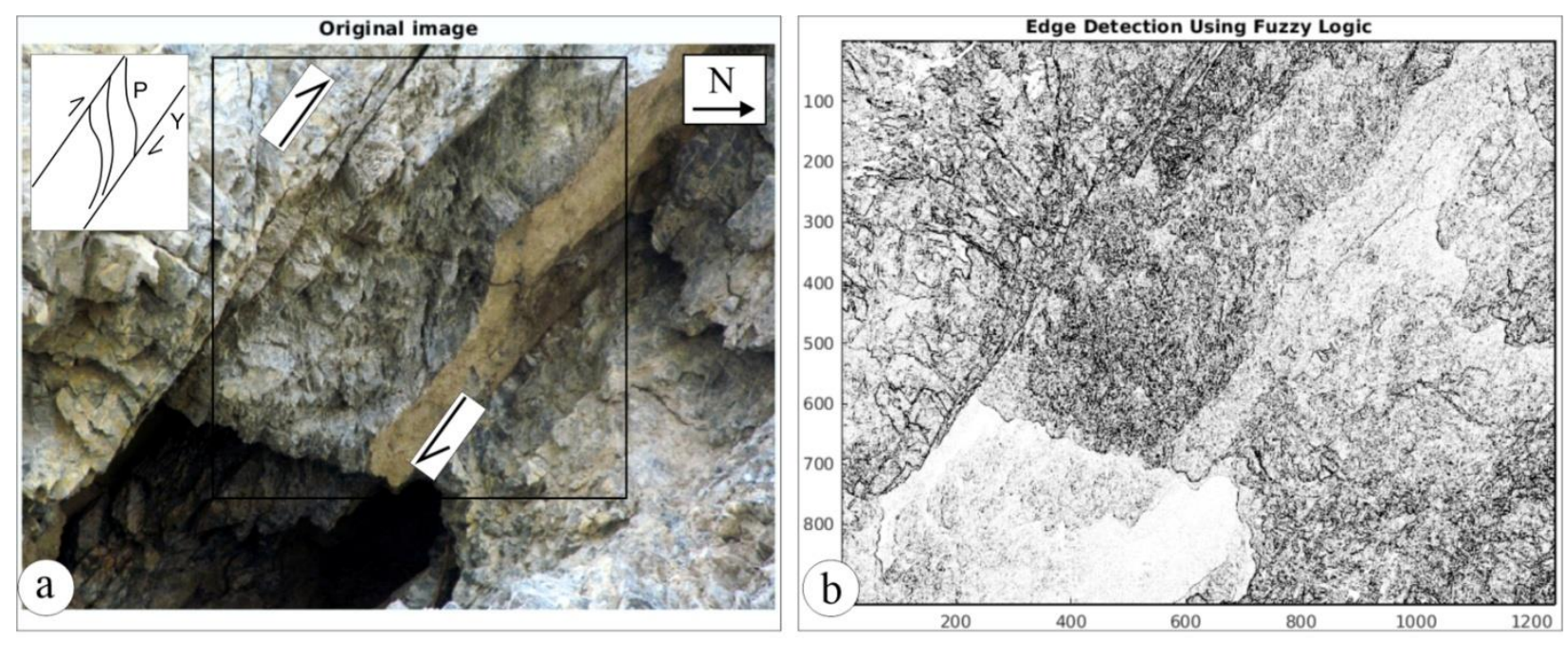

Fig. 4. See Table 1 for the codes. (a) Aca, (b) Bcf. Width of image 1.5 m. Mandhali Formation. Limestone exposed at $30.6802^{\circ} \mathrm{N}, 78.3497^{\circ} \mathrm{E}$.

\section{Discussions}

In the image segmentation method $(\operatorname{method} A)$, no significant differences are found amongst the

147 uninterpreted image (Fig. 2a), the contrast stretched image (Fig. 2b), and the greyscale image

148 (Fig. 2c). No significant improvement is found also for fuzzy logic image processing (method $B$ )

149 when the RGB to greyscale conversion was made (image Bab in Repository 2). However, in case

150 of the segmented crack approach under method $B$, curvature of the P-plane is clearly visible near

151 the middle part of the image (Fig. 2d). The cleaned image (Fig. 2e) under method $B$ shows

152 fractures with equal ease as that of the Fig. 2d. When Fuzzy logic image processing (method $B$ )

153 with Ix: gradient of intensities is applied, shear zones take an appearance (Fig. 2f), which

154 perhaps only a structural geologist who has seen the field exposure (Fig. 2a) earlier can interpret.

155 However, when Fuzzy logic image processing (method $B)$ with $\mathrm{I}_{\mathrm{y}}$ : gradient of intensities is

156 applied, the shear planes are not at all decipherable (image Bad in Repository 2), even though we

157 have a prior idea about the original uninterpreted image (Fig. 2a). One of the best manifestations

158 of $\mathrm{P}$ and Y planes appear when edge detection using fuzzy logic is applied (Fig. 2g). In this case, 
159 the right portion of the image demonstrates both the $\mathrm{P}$ and the Y planes quite distinctly. When

160 bilateral filtering $(\operatorname{method} C)$ is done and different steps applied, there is no significant

161 improvement in identifying the brittle planes $\mathrm{Y}$ and $\mathrm{P}$ in the obtained images (image Caa up to

162 Cae in Repository 2) when compared with the uninterpretd image (Fig. 2a). The LoG (image

163 Dag in Repository 2) and the zerocross (image Dah in Repository 2) processes yield clumsy

164 output and can be more difficult to identify the planes $\mathrm{Y}$ and $\mathrm{P}$, than the simple uninterpreted

165 image (Fig. 2a). The Prewitt filter (Fig. 2h) and the Roberts filter (Fig. 2i) filter give better and

166 cleaner images.

167

168 Interestingly, when we apply image the segmentation method (method $A$ ) over another

169 uninterpreted image (Fig. 3a), segmented crack (image Abd in Repository 2) and cleaned images

170 (image abe in Repository 2) are impossible to decipher for Y and P planes and the shear sense.

171 All the approaches of fuzzy logic image processing (method B) applied on Fig. 3a gives

172 unsatisfactory images (images $B b a$ to $B b f$ in Repository 2) that cannot be interpreted for $\mathrm{Y}$ and $\mathrm{P}$

173 planes. The same is true for the resultant images (images $C b a$ to $C b e$ ) in Repository 2) when

174 bilateral filtering method is applied on Fig. 3a. Comparison between various fracture detection

175 filter techniques (method D) when applied on Fig. 3a, LoG (image Dbg in Repository 2) and

176 Zerocross filters (image $D b h$ in Repository 2) give the worst results. The Sobel filter here can

177 produce an image where few of the shear planes are visible (Fig. 3b), but still difficult to

178 interpret than the simple visual interpretation of Fig. 3a.

179

180 
181 In case of the field photograph Fig. 4a, following the image segmentation method $(\operatorname{method} A)$ the

182 segmented crack and the cleaned crack filters give white patches at the place where P- and Y

183 planes are found otherwise. In Fuzzy logic image processing (method $B$ ), only the edge detection

184 technique reveals $\mathrm{P}$ and Y planes somewhat clearly (Fig. 4b). The same problem persists in all

185 the output images (images Dca to Dch in Repository 2) in using the method of comparison

186 between various fracture detection filter techniques (method $D$ ). In bilateral filtering method

187 (method $C$ ), none of the output images (images $C c a$ to $C c e$ in Repository 2) give clear-cut P and

188 Y planes. The different techniques applied for image analyses in this study needs to be cross-

189 checked for other rock types such as gneisses.

191 The main difference between the two field snaps Figs. 2a and 3a is that in the later, the P-planes

192 are more closely spaced than the former one. Possibly because of this, Fig. 2a after image

193 processing, gave more distinct appearance of $\mathrm{P}$ and $\mathrm{Y}$ planes in few cases. Fig. 4a is a case with

194 white fault gouge developed where P- and Y planes are found. Because of this white colour,

195 many of the filtering approaches failed to pick up the $\mathrm{Y}$ and the P-planes, even though those are

196 visible to the eyes of a trained structural geologist! For all the three starting images Figs. 2a, 3a

197 and 4a, their greyscale images deduced by various means do not significantly ease the detection

198 of P and Y planes. In some of the methods, the thinned images and the zerocross images (e.g., 199 images Aaf and Dch, respectively, in Repository 2) completely fail to bring out the Y and the P200 planes.

201

202

203 


\section{Conclusions}

205 A number of image enhancement methods, techniques and filters are available. Testing them on 206 meso-scale photographs of brittle shear zones, led to understand the followings.

207 (i) One of the best manifestation of $\mathrm{P}$ and $\mathrm{Y}$ planes appear when edge detection using fuzzy logic is applied.

(ii) The zerocross and the thinned image techniques usually give poor ouput.

(iii) Greyscale images do not significantly enhance the photographs.

(iv) If the rock consists of white fine grained contents such as gouge material, image enhancement to detect brittle planes may not work well. field snaps can be more useful! In case, image processing also give ambiguous results, it will be better to undertake conventional thin-section studies of rocks to detect $\mathrm{P}$ and $\mathrm{Y}$ planes in microscale.

Acknowledgements: This work is a part of PH's research assignment for the course GS 407:

221 Structural Geology taught by SM. CPDA grant (IIT Bombay) supported SM. An anonymous

222 reviewer commented. Handled by Saibal Gupta. This article is dedicated to Prof. W-C Dullo and 223 his wife Monika Dullo for decades of selfless service for the International Journal of Earth 224 Sciences (formerly Geologische Rundschau) as Chief Editor and Managing Editor, respectively.

\section{Author credit statement:}


227 PH: Programming and output images. SM: Supervision, manuscript writing, fieldwork. NB:

228 Fieldwork, photography, commenting on the draft.

229 


\section{References}

231 Biswas T, Bose N, Dutta D and Mukherjee S 2022 Arc-parallel shears in collisional orogens:

232 Global review and paleostress analyses from the NW Lesser Himalayan Sequence (Garhwal 233 region, Uttarakhand, India); Marine Petrol. Geol. in press.

235 Biswas T, Mukherjee S 2022 Non-Uniform B-spline curve analyses of sigmoid brittle shear P236 and ductile shear S-planes; Int. J. Earth Sci. in press.

238 Bjørnerud M G and Boyer B. 1996 Image Analysis in Structural Geology Using NIH Image; In:

239 Structural Geology and Personal Computers (ed.) De Paor D, Pergamon Press. Oxford. ISBN: 0 24008042430 9. pp. 105-122.

242 Bons P D and Jessell M 1996 Image Analysis in Structural Geology Using NIH Image; In:

243 Structural Geology and Personal Computers (ed.) De Paor D, Pergamon Press. Oxford. ISBN: 0 24408042430 9. pp. 135-166.

246 Bose N, Dutta D and Mukherjee S 2018 Role of grain-size in phyllonitisation: Insights from 247 mineralogy, microstructures, strain analyses and numerical modeling; J. Struct. Geol. 112 39-52.

249 Bose N and Mukherjee S 2019 Field documentation and genesis of the back-structures from the 250 Garhwal Lesser Himalaya, Uttarakhand, India. In: Crustal Architecture and Evolution of the 251 Himalaya-Karakoram-Tibet Orogen. (eds) Sharma R, Villa I M and Kumar S, Geol. Soc. London 252 Spec. Publ. 481 111-125. 
253 Dutta D and Mukherjee S 2019 Opposite shear senses: Geneses, global occurrences, numerical 254 simulations and a case study from the Indian Western Himalaya; J. Struct. Geol. 126 357-392.

255

256 Genge M J 2020 Geological Field Sketches and Illustrations: A Practical Guide. Oxford 257 University Press. ISBN 978-0-19-883592-9. pp. 1-293.

258 Healy D et al 2017 FracPaQ: A MATLAB ${ }^{\mathrm{TM}}$ toolbox for the quantification of fracture patterns; 259 J. Struct. Geol. 95 1-16.

Heilbronner R and Barrett S 2014 Image Analysis in Earth Sciences: Microstructures and

263 Textures of Earth Materials. Springer-Verlag. Berlin. pp. 13. ISBN: 978-3-642-10342-1.

Internet ref: www.mathworks.com （Accessed on 25-May-2021)

Misra A A and Mukherjee S 2018 Seismic Structural Analysis. In: Atlas of Structural Geological

270 Interpretation from Seismic Images (eds.) Misra A A, Mukherjee S, Wiley Blackwell. ISBN:

271 978-1-119-15832-5. pp. 15-26.

272

273 Mokhles M, Fatai A and Mohammed M 2019 Advances in Rock Petrography: Image Processing

274 Techniques for Automated Textural Thin Section Analysis; Society of Petroleum Engineers. SPE275 194835-MS.

276

277 Mukherjee S 2021 Atlas of Structural Geology. Second Edition. Elsevier. Amsterdam.

278 ISBN: 978012816802. pp. 1-260. 
279 Novakova L and Pavlis T L 2017 Assessment of the precision of smart phones and tablets for 280 measurement of planar orientations: A case study; J. Struct. Geol. 97 93-103.

281

282 Passchier C W and Trouw R A J 1996 Microtectonics. Springer. pp. 128. ISBN: 978-3-662-

$283 \quad 08736-7$.

284

285 Sulaksana N and Hamdani A M 2014 The Analysis of Remote Sensing Imagery for Predicting

286 Structural Geology in Berau Basin East Kalimantan; Int. J. Sci. Res. 18-21. Article id:

287020131349.

288

289 Repository material: On request to the author S Mukherjee (soumyajitm@gmail.com,

290 msoumyajit@yahoo.com , repository item will be shared) 